
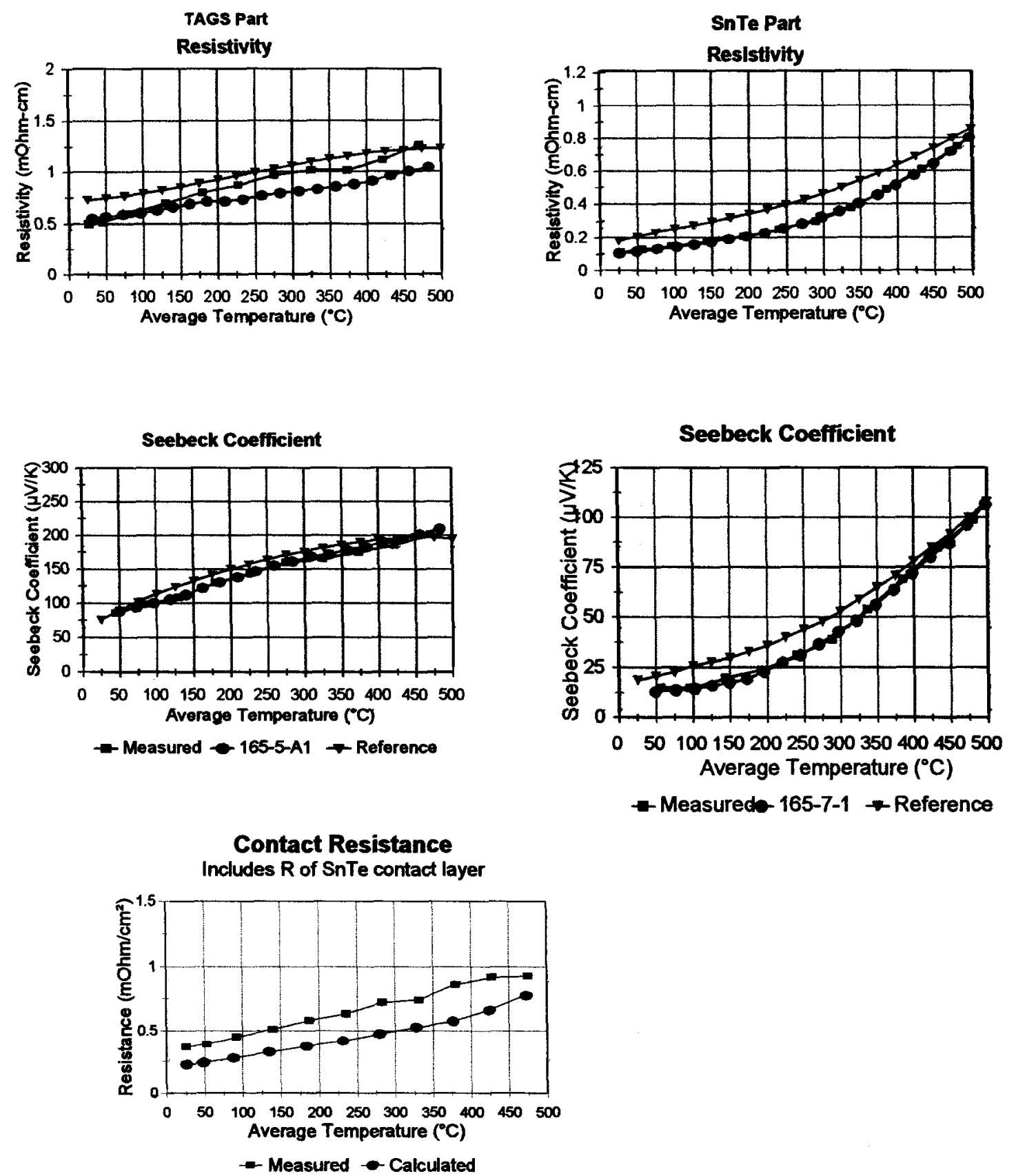

Figure 7. Resistivity and Seebeck Coefficient for Segments of Sample 166-113 (TAGS/SnTe) and Contact Resistance at Joint 
Although an indication of the resistance of the joint is obtained using the fixed probes, the accuracy of the measurement is uncertain for two reasons. First the fixed probes spanning the joint also include some TAGS and SnTe of the adjacent segments. In principle the resistance of this material can be calculated as was done to produce the curve labeled "Calculated" on the graph showing the Contact Resistance. This curve assumes the "fully dense" thickmess of SnTe in the joint and that it has the bulk value of resistivity, and that the remaining distance between the probes (actually the remaining distance between the center of the holes in which the probes are inserted) is made up of half TAGS and half SnTe. The second uncertainty, and probably the more serious one, is determining the "effective" distance between these probes. The diameter of the holes into which the thermocouples are inserted is $0.4 \mathrm{~mm}$, and this hole is essentially filled with metal, i.e. with a material with significantly higher conductivity that the surroundings, which distorts the current flow in this region. With widely spaced probes, this distortion is insignificant, but for holes with spacing comparable to the hole diameter it is not. In sample 166-133, the spacing between the centers of the holes $0.88 \mathrm{~mm}$. Hence the "contact resistance" data of Figure 7 only says that this resistance is not major.

The measurement described above in Section 2.1, in which the sample is translated under a fixed voltage probe, is better suited to evaluate the contact resistance. This measurement, however, at least with the apparatus we have available, can only be made at room temperature. Figure 8 shows the results of this measurement made on 166-113 and verifies that the contract resistance between TAGS and SnTe is completely negligible. The resistivity of these two materials, calculated from the slopes of the segments are 0.55 and $0.10 \mathrm{~m} \Omega-\mathrm{cm}$ respectively.

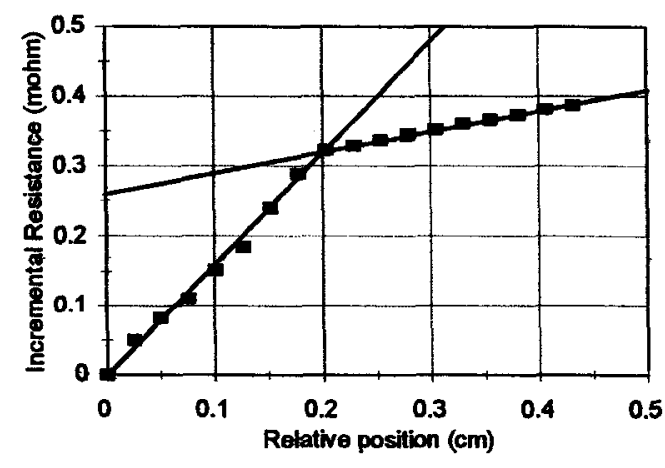

Figure 8. Incremental Resistance on Face of Segmented Sample 166-113 (TAGS/SnTe) Across Joint

An SEM image was taken of a metallographic cross section of the joint in sample 166-105 and is shown in Figure 9. Several observations should be made about this figure. First, the junction region (2) is $\sim 70 \mu \mathrm{m}$ thick, as compared with the nominal, "fully dense" value of $110 \mu \mathrm{m}$ which we expected. Of course the junction thickmess may not be completely uniform on the scale of 10's of $\mu \mathrm{m}$ 's, and it may be thicker in other regions. The small-scale cracking seen in the TAGS (3) is somewhat surprising, primarily in the fact that it apparently does not affect the measured resistivity. In addition the mechanical strength of the samples after joining argues that the cracking is for the most part local or else is an artifact of the grinding and polishing of this sample. The density of the junction region and its continuity with the SnTe and TAGS is also very encouraging. 


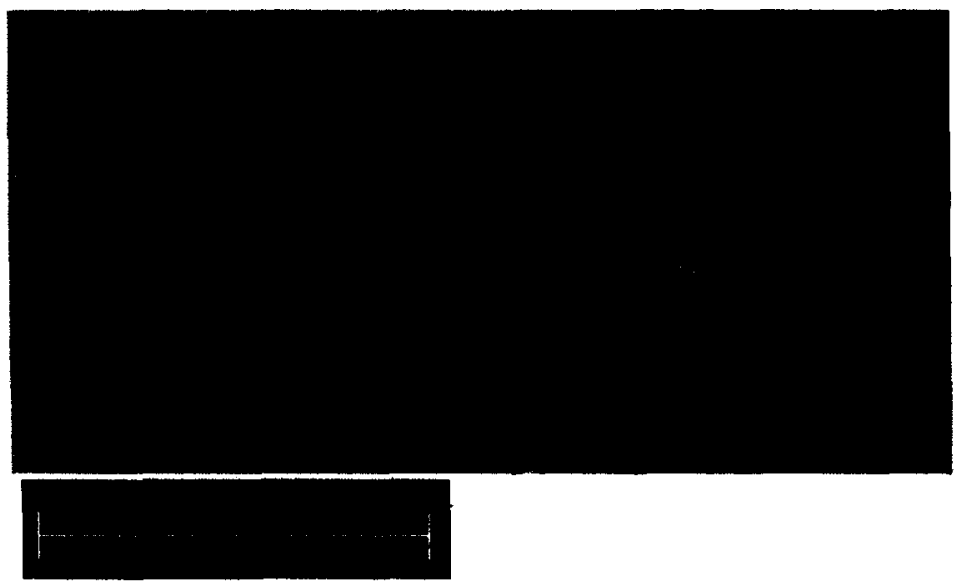

Figure 9. SEM Image of Joint Region of Sample 166-105 1: SnTe, 2: Joint, 3: TAGS

\subsection{DEVELOPMENT OF EL,ECTRODES}

For initial evaluation of segmented legs in the ceramic eggcrate we were prepared to use pressure contacts and postpone the development of more monolithic contacts to Phase II. However since thermal-sprayed contacts are used on Hi-Z's commercial $\mathrm{Bi}_{2} \mathrm{Te}_{3}$ modules this process was tested on the materials we are using, TAGS, SnTe and PbTe. Initial layers of molybdenum, $0.15 \mathrm{~mm}(0.006 ")$ were sprayed on samples of these materials. Excellent adherence was obtained on all samples except for one surface on a TAGS sample where the Mo separated from the TAGS while the excess material on its sides ground off (by hand on \#240 grit 3M "WETORDRY TRI-MITE" paper). For all other samples, including two other TAGS samples, it was not possible to separate this layer by probing and lifting the interface with a sharp needle or tweezers.

The contact resistances of these layers to the TAGS, SnTe and $\mathrm{PbTe}$ were measured at room temperature on rectangular bars of the materials by making two point contact connections to the Mo layers deposited on both ends of the bar. One served as a current lead and the other a voltage probe. Four-probe measurements of the resistance of the sample plus contact showed no additional resistance above that expected from the sample itself; contact resistance was negligible.

\subsection{CALCULATIONS OF EXPECTED PERFORMANCE}

A series of calculations was made to determine the expected performance of the two-couple module with legs areas of $0.56 \times 0.56 \mathrm{~cm}^{2}$ and lengths of $0.61 \mathrm{~cm}$. These calculations were made using a computer code developed at Hi-Z which uses as input the temperature-dependant materials-properties (Seebeck Coefficient, electrical resistivity and thermal conductivity), the hot- and cold-side temperatures, the leg dimensions and the number of couples. The code calculates the segment lengths necessary which yield the maximum couple efficiency. It also calculates the output 
voltage, current and power and the value of the load resistance which yields maximum power output. The code does not include the effects of electrical losses due to contact resistance or thermal losses due to by-pass heat flow in supporting structures. Typically these losses reduce the efficiency by 1 or 2 percentage points.

Table 5 shows the results of these calculations for TAGS/SnTe $p$ legs and 2N/3N $\mathrm{PbTe} n$ legs for various hot- and cold-side temperatures and for two different maximum temperatures of the TAGS segment.

It was decided to be conservative and design the test module to operate at a cold side of $\sim 50^{\circ} \mathrm{C}$ and to limit the maximum temperature of the TAGS to less than $400^{\circ} \mathrm{C}$. Thus the TAGS and SnTe segments would have approximately equal lengths. 2N/3N $\mathrm{PbTe}$ samples with the cold segment approximately 20 longer than the hot segment were available in the in the stock of PbTe legs fabricated previously.

\subsection{FABRICATION OF EGGCRATES}

Eggcrate fabrication was carried out by Quest Technology, LP, the subcontractor on this project, using a proprietary ceramic injection molding process they have developed. For the initial studies reported here a four-pocket (two-couple) eggcrate was chosen since it would include all of the features needed in larger eggcrates. The pockets in the eggcrate were to accommodate legs $5.5 \mathrm{~mm}$ square by $6.1 \mathrm{~mm}$ long $\left(0.22^{\prime \prime} \times 0.22^{\prime \prime}\right.$ $\left.\times 0.24^{\prime \prime}\right)$. Walls were to be $0.38 \mathrm{~mm}\left(0.015^{\prime \prime}\right)$ thick. The height of selected walls, one wall on the cold side and two on the hot side, was reduced by $0.38 \mathrm{~mm}$ to provide cross-over ( $n$ to $p$ ) interconnects between the legs so that all four legs would be electrically in series. The primary challenge of this design is the small ratio of wall thickness to wall extent.

A steel injection molding tool was fabricated using electric discharge machining to serve as the mold for the eggcrate. Its size was adjusted to compensate for the shrinkage which occurs when the green molded part is sintered. Attempts to fabricate the eggcrate using this tool were not successful for two reasons, both associated with its very thin walls. Injection of the ceramic/binder slurry, even using the finest powders available, required very high pressures which resulted in excessive compaction of the ceramic at the input end of the tool. In some cases even at high pressure complete filling of the tool was not achieved. In others ejection of the green part was affected with the material especially in the vicinity of the input end being left in the tool.

Two changes were made in the design of the eggcrate and of the tool to aid in the successful ejection of the green part. In the original tool ejection pins were included at each wall intersection. Since the diameter of the ejection pins was greater than the wall thickmess, this resulted in the comers of the completed crate being filled with small "quarter-rounds," which could be accommodated by removal of a small (a few mils) amount of material from the corners of the legs. To improve ejection additional pins were placed mid-way between the original pins which results in "half-rounds" in the middle 
Table 5

Calculated Performance for a Two-couple Module with TAGS/SnTe $p$ legs and 2N/3N PbTe $n$ legs. Leg Area: $0.56 \times 0.56 \mathrm{~cm}^{2}$; Length: $0.61 \mathrm{~cm}$.

$$
\mathrm{T}_{\mathrm{bot}}=550^{\circ} \mathrm{C}
$$

\begin{tabular}{|c|c|c|c|c|c|}
\hline \multicolumn{6}{|c|}{ TAGS@ $<450^{\circ} \mathrm{C}$} \\
\hline $\mathrm{T}_{\text {cold }}\left({ }^{\circ} \mathrm{C}\right)$ & 250 & 100 & 50 & 25 & 0 \\
\hline Efficiency (\%) & 6.2 & 10.1 & 11.2 & 11.6 & 12.1 \\
\hline$V$ (volts) & 0.134 & 0.191 & 0.205 & 0.211 & 0.216 \\
\hline I (amps) & 6.76 & 11.48 & 13.27 & 14.12 & 15.03 \\
\hline P (watts) & 0.907 & 2.195 & 2.724 & 2.973 & 3.247 \\
\hline$R_{\text {load }}(\mathrm{m} \Omega)$ & 19.8 & 16.6 & 15.5 & 14.9 & 14.4 \\
\hline $\mathrm{T}_{\mathrm{J}}^{\mathrm{P}}\left({ }^{\circ} \mathrm{C}\right)$ & 448 & 447 & 450 & 445 & 446 \\
\hline $\mathrm{T}^{\mathrm{P}}{ }_{\mathrm{J}}\left({ }^{\circ} \mathrm{C}\right)$ & 352 & 330 & 320 & 319 & 319 \\
\hline $\mathrm{l}_{\mathrm{p}, \mathrm{hor}}(\mathrm{cm})$ & 0.309 & 0.130 & 0.205 & 0.206 & 0.198 \\
\hline $1_{p, \text { cold }}(\mathrm{cm})$ & 0.300 & 0.379 & 0.404 & 0.403 & 0.411 \\
\hline $\mathrm{l}_{\mathrm{n}, \mathrm{hot}}(\mathrm{cm})$ & 0.434 & 0.307 & 0.278 & 0.260 & 0.245 \\
\hline $1_{n, \text { cold }}(\mathrm{cm})$ & 0.175 & 0.301 & 0.331 & 0.347 & 0.364 \\
\hline
\end{tabular}

\begin{tabular}{|c|c|c|c|c|c|}
\hline $\mathrm{T}_{\text {cold }}\left({ }^{\circ} \mathrm{C}\right)$ & 250 & 100 & 50 & 25 & 0 \\
\hline Efficiency (\%) & 5.6 & 9.4 & 10.6 & 11.0 & 11.5 \\
\hline V (volts) & 0.121 & 0.183 & 0.198 & 0.203 & 0.208 \\
\hline I (amps) & 6.99 & 11.48 & 13.20 & 14.07 & 14.93 \\
\hline$P$ (watts) & 0.849 & 2.100 & 2.608 & 2.860 & 3.113 \\
\hline$R_{\text {load }}(m \Omega)$ & 17.4 & 15.9 & 15.0 & 14.4 & 14.0 \\
\hline $\mathrm{T}^{\mathrm{P}}{ }_{\mathrm{J}}\left({ }^{\circ} \mathrm{C}\right)$ & 400 & 397 & 400 & 398 & 396 \\
\hline $\mathrm{T}^{\mathrm{N}}{ }_{3}\left({ }^{\circ} \mathrm{C}\right)$ & 349 & 325 & 320 & 319 & 319 \\
\hline$l_{p, h o t}(\mathrm{~cm})$ & 0.416 & 0.326 & 0.297 & 0.289 & 0.284 \\
\hline $1_{p, \text { cold }}(\mathrm{cm})$ & 0.192 & 0.285 & 0.313 & 0.319 & 0.326 \\
\hline $1_{\text {nhot }}(\mathrm{cm})$ & 0.439 & 0.314 & 0.279 & 0.262 & 0.245 \\
\hline $1_{n, \text { cold }}(\mathrm{cm})$ & 0.170 & 0.296 & 0.331 & 0.347 & 0.364 \\
\hline
\end{tabular}


of each wall in each pocket. These are accommodated by cutting small groves in the sides of the legs. This is acceptable for a handfabricated module, but alternate solutions will have to be found for future production modules. The second change was to taper the side of the walls by about $1^{\circ}$, resulting in a wall thickness in the eggcrate varying from $3.8 \mathrm{~mm}$ on the hot side to $6.1 \mathrm{~mm}$ on the cold side (0.015 to $\left.0.024^{\prime \prime}\right)$

Using this re-manufactured tool, acceptable eggcrates were fabricated. Some the were distorted during sintering, probably due to excessive compaction in the tool, but Figure 10. Injection-molded Ceramic others sintered successfully and were used to fabricate modules. Figure 10 shows one of the completed eggcrates.

\subsection{SEGMENTING LEGS FOR EGGCRATE}

\section{TAGS/SnTe}

Based on the results of the test series described above, it was decided to fabricate the TAGS/SnTe legs using parameters close to those used in fabricating sample 166-105 and 166-113. From the calculations described in Section 2.7 the lengths of the TAGS and SnTe segments were chosen to be equal. The design length of the legs is $0.61 \mathrm{~cm}$ yielding segments lengths of $0.30 \mathrm{~cm}$ with a $100 \mu \mathrm{m}$ joint thickmess. Because the walls of the eggcrate are slightly tapered it was decided to taper the elements similarly. Although straight elements could have been used, and very well may be when many multi-element modules are fabricated, tapered elements were chosen since this facilitates holding the elements while applying the contacts. (Hi-Z's polymer eggcrate accomplishes the same function by having a small lip on one side of each pocket which prevents elements from falling through.) Legs were cut with parallel sides $0.61 \times 0.61$ $\mathrm{cm}$. and after bonding were tapered. This also allowed using the same graphite tooling which had originally been built to develop the segmenting parameters.

Because of their relatively short length two segmented legs were joined simultaneously with one stacked above the other in the die. A piece of 0.38-thick grafoil was placed between the two legs in the die. After the segments were joined the resistance as a function of position on the side of the sample was measured using the moving probe. This verified that the resistivities of the TAGS and SnTe were as expected and that the contact resistance was negligible. The effective "room temperature" Seebeck Coefficient was also verified in the 25 to $100^{\circ} \mathrm{C}$ test rig.

The segmented legs were then tapered ( $1^{\circ}$ on a side) using a small drum sander (320 grit) in a laboratory milling machine. Small groves were filed by hand in the sides of the legs to accommodate the ridges in the eggcrate necessitated by the ejection pins. 


\section{PbTe Legs}

As indicated earlier the $\mathrm{n}$ legs used for these test modules were fabricated previously at General Atomic. These segmented legs were also screened for room temperature resistance as a function of distance along their length and for effective Seebeck Coefficient. Suitable samples were tapered and grooved.

\subsection{ASSEMBLY OF MODULES.}

The eggcrates with legs inserted were mounted in a jig and a layer of Mo was thermal-sprayed first onto the cold side and then onto the hot side. $0.25 \mathrm{~mm}$ was used on the cold side and $0.50 \mathrm{~mm}$ on the hot. Figure 11 shows a the cold side of a module after spraying. The surfaces were then ground flat down to the tops of the walls of the eggcrate which separated the unwanted bridging connections between legs. The connection pattern is shown photographs of the module in Figure 12. One minor

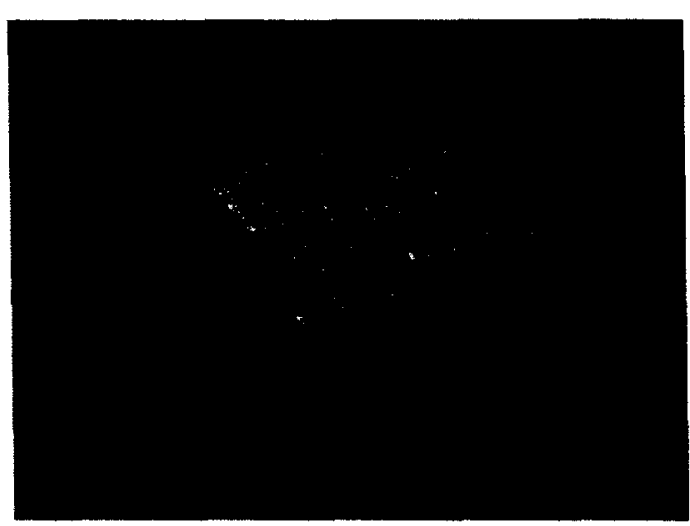

Figure 11. Cold Side of Module After Spraying with Mo

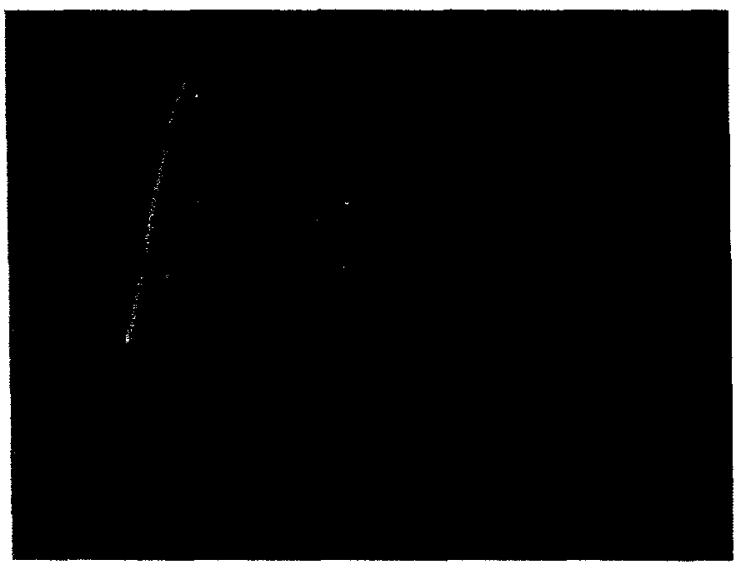

a)

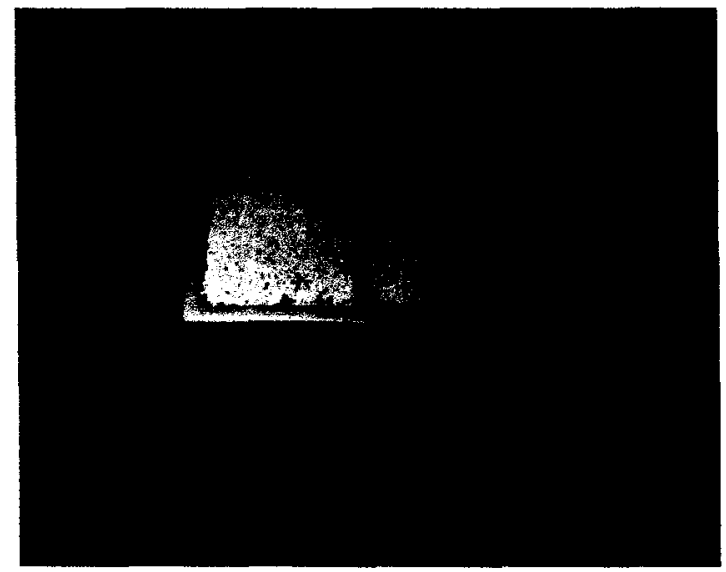

b)

Figure 12. Module Surfaces After Spraying and Grinding a) Hot Side; b) Cold Side 


\subsection{SUMMARY AND CONCLUSIONS}

The primary goal of this Phase I program has been accomplished: to demonstrate a ceramic, injection-molded eggcrate which will form the support structure for a closespaced thermoelectric module which can operate at significantly higher temperatures than presently possible with such modules. It has been shown that yttria-stabilized zirconia is compatible at high temperatures with typical thermoelectric materials (TAGS, SnTE and PbTe) and that it can serve as a barrier between them to preclude crosscontamination and doping of the constituents of one leg type by those from the other. Using a $2 \times 2$ ceramic eggcrate, thermally sprayed molybdenum electrodes have been deposited on a test module which effectively seal each pocket, further reducing the possibility of migration of elements.

Based on these results the next tasks are to refine the design of the injection tool and the injection parameters to produce consistent results and to allow increase in the size of the module to that on which commercial, high-temperature thermoelectric modules can be based. In addition, development of the fabrication techniques for segmented thermoelectric legs for use with these ceramic eggcrates at high temperatures must be continued. 


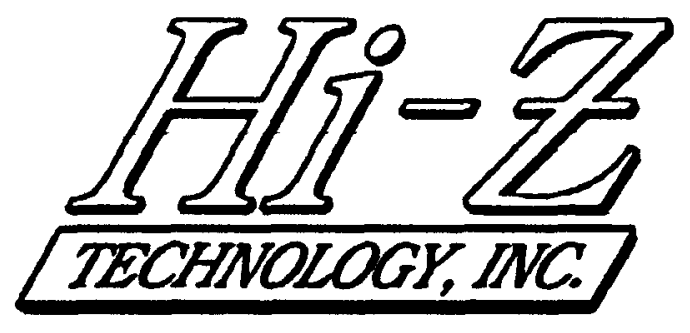

THERMOELECTRIC MATEIRALS •DEVICES • SYSTEMS

\title{
Insulators and Materials for Close-Spaced Thermoelectric Modules
}

\section{HZ-4002 - Final Report}

\author{
Prepared by \\ D. Snowden \\ Prepared for \\ United States Department of Energy \\ Contract DE-FG03-02ER83455 \\ Period: July 22, 2002 through April 2, 2003 \\ DOE Program Manager: Lisa C. Herrera
}


Table of Contents

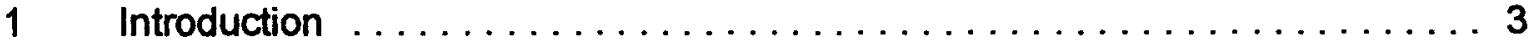

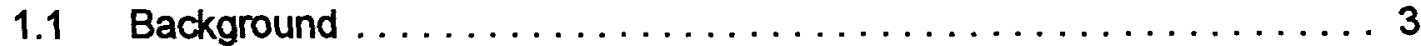

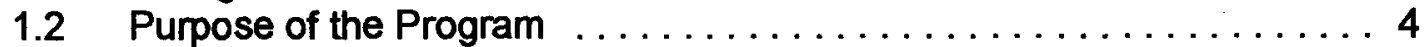

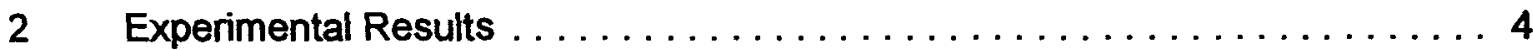

2.1 Compatibility of Yttria-Stabilized Zirconia With Thermoelectric

Materials ........................... 4

2.2 Materials Fabrication . . . . . . . . . . . . . . . . . . 10

2.3 Sample Preparation and Evaluation $\ldots \ldots \ldots \ldots \ldots \ldots \ldots \ldots \ldots$

2.4 Joining of TAGS and SnTe . . . . . . . . . . . . . . . 12

2.5 Measurement of Resistivity and Seebeck Coefficient .......... 13

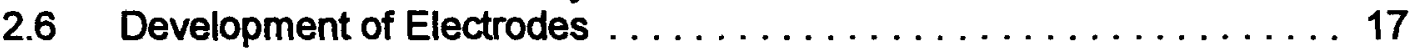

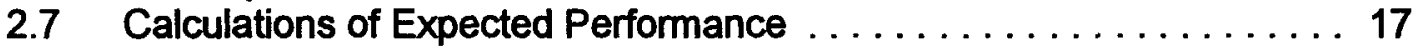

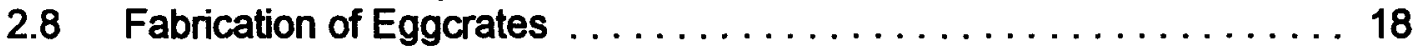

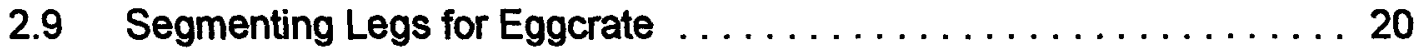

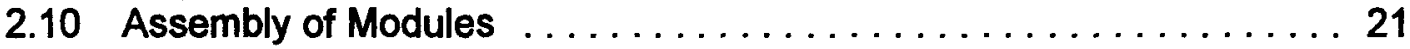

$3 \quad$ Summary and Conclusions $\ldots \ldots \ldots \ldots \ldots \ldots \ldots \ldots \ldots \ldots \ldots$

\section{List of Figures}

1 Eggcrate and $\mathrm{HZ}-14$ Thermoelectric Module $\ldots \ldots \ldots \ldots \ldots \ldots \ldots$

2 Configuration of Graphite Chamber used in Long-Term Diffusion Tests . . . . 5

3 Resistivity and Seebeck Coefficient of TAGS Sample 165-5 A1, Before and After 2835 Hour Diffusion Test at $500^{\circ} \mathrm{C} \ldots \ldots \ldots \ldots \ldots \ldots \ldots$

4 Room Temperature Resistance of Segmented PbTe Sample as a Function of Position on Surface Before and After 2834 Hour Test at $500^{\circ} \mathrm{C} \ldots \ldots \ldots . .8$

5 Temperature Dependence of Resistivity and Seebeck Coefficient of TAGS Sample $165-5$ A2 . . . . . . . . . . . . . . . . . . . . . 11

6 Temperature Dependence of Resistivity and Seebeck Coefficient of SnTe

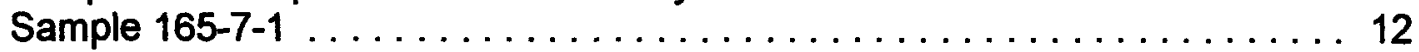

7 Resistivity and Seebeck Coefficient for Segments of Sample 166-113 . . . . 15

8 Incremental Resistance on Face of Segmented Sample 166-113 Across Joint . . . . . . . . . . . . . . . . . . . . . . . . . . 16

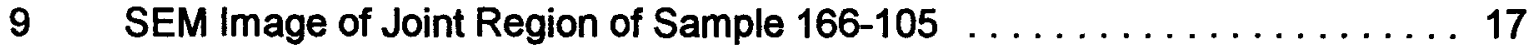

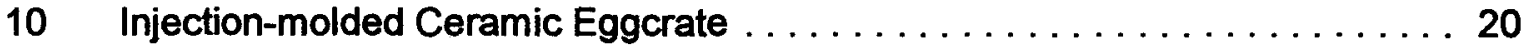

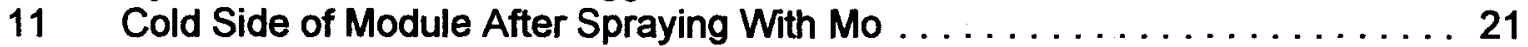

12 Module Surfaces After Spraying and Grinding ............... 21 


\subsection{INTRODUCTION}

\subsection{BACKGROUND}

A significant number of new commercial markets have been opening up in the last few years which utilize thermoelectric generators for power generation in special locations and circumstances, such as when large quantities of waste heat are available or when conventional power sources are not present. Presently the only commercially available, off-the-shelf thermoelectric modules use $\mathrm{Bi}_{2} \mathrm{Te}_{3}$ alloys as the thermoelectric elements. Use of this material limits the hot-side temperature to $\sim 250$ to $300^{\circ} \mathrm{C}$ and yields a conversion efficiency of $\sim 5 \%$. In spite of these limitations the market for these modules has been growing and new uses are being developed for several reasons: modules are self contained, are easy to mount to the heat source and cold-side heat sink, are available in various power ratings, and can be interconnected in various series or parallel configurations to provide the needed voltage and current.

Many other thermoelectric materials with higher temperature capabilities are known and some have been used in a variety of thermoelectric generators for several decades. These generators however have been designed and built primarily for special purposes, such as radioisotope-fueled generators for outer-planet space missions; no simple off-the-shelf thermoelectric modules exist using these materials. However, if such a module were developed it is clear that it would have a significant market. Applications which are not economically feasible with the present limits on efficiency and specific power output of $\mathrm{Bi}_{2} \mathrm{Te}_{3}$ modules could become viable with increases in these quantities.

The close-spaced modules built and sold by Hi-Z Technology utilize a polymer "eggcrate" (Figure 1) which supports the thermoelectric $n$ and $p$ legs in the configuration of a square pancake which is sandwiched between the hot- and cold-surfaces to provide the temperature gradient across the device. The eggcrate also supports the electrical inter-connects between the $n$ and $p$ legs.

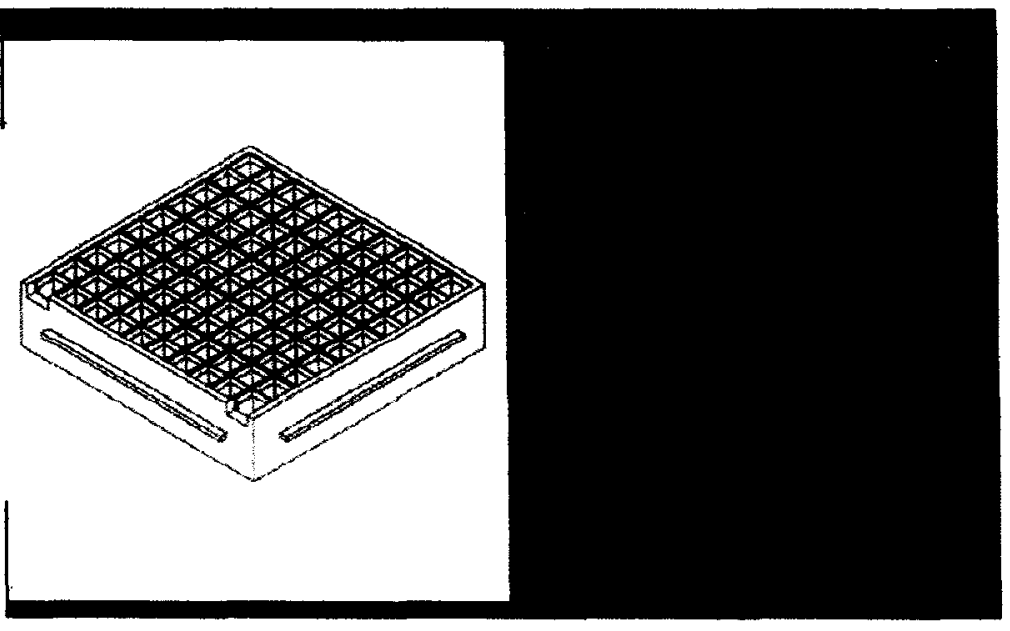

The polymer eggcrate concept Figure 1. Eggcrate and HZ-14 Thermoelectric has been very successful for Module. The eggcrate openings are loaded with low temperature operation but $\mathbf{n}$ or $\mathbf{p}$ legs, metallized, and surface finished. The cannot be used with polymer eggcrate can only operate to $300^{\circ} \mathrm{C}$. thermoelectric generators 
which operate at higher temperatures since the polymer begins to degrade at around $300^{\circ} \mathrm{C}$. Eggcrates for operation at higher temperatures have been built of interlocking sheets of mica, but

(1) These do not have the mechanical rigidity needed to provide good support for the module.

(2) Fabrication of these eggcrates is expensive.

(3) Most importantly, the eggcrate must be constructed in a manner that prevents "cross-talk" between adjoining $n$ and $p$ legs, i.e., no diffusion through the eggcrate walls should occur and the mica interlocking assembly process must be avoided because electrical shorts and/or opportunities for surface diffusion have been observed to occur and cause degradation.

\subsection{PURPOSE OF THE PROGRAM}

A major purpose of this Phase I research was to evaluate the feasibility of developing an "eggcrate" structure to hold the elements of a thermoelectric generator in a close-spaced configuration which could be operated at a hot-side temperature of $550^{\circ} \mathrm{C}$, similar in function to the polymer eggcrate used by Hi-Z Technology in its commercial $\mathrm{Bi}_{2} \mathrm{Te}_{3}$ based generators which have a hot-side temperature up to $300^{\circ} \mathrm{C}$. The second goal was to fabricate and test segmented legs suitable for use in that higher temperature generator.

Two possible configurations for the eggcrate were proposed. The first was to be injection-molded of yttria-stabilized zirconia, a high temperature ceramic with low electrical and thermal conductivity. The second was to be assembled of composite sheets of mica-tungsten-mica, slotted to interconnect with one another in an eggcrate configuration. This second configuration was to be the back-up if the zirconia was found to be unsuitable for use with the thermoelectric materials or if the injection molding process was unsuccessful.

In the second task materials for the segmented legs were chosen and the legs for use with the eggcrate were designed and fabricated which would provide as high an efficiency as possible; these legs were assembled into a close spaced $(2 \times 2)$ module. SnTe and TAGS were chosen for the hot- and cold-side segments of the $p$ leg; $3 \mathrm{~N} \mathrm{PbTe}$ and $2 \mathrm{~N}$ PbTe were chosen for the $n$ leg.

\subsection{EXPERIMENTAL RESULTS}

\subsection{COMPATIBIITY OF YTTRIA-STABILIZED ZIRCONLA WITH THERMOELECTRIC MATERIALS}

Before proceeding with the development of a zirconia, injection-molded eggcrate, it was important to verify that no adverse reactions occurred between the zirconia and the thermoelectric elements and also to determine if any significant diffusion of elements could take place through the zirconia, allowing cross contamination and inadvertent, 
harmful doping of adjacent legs. The primary concern for the couples chosen for use in the present program [p-leg: SnTe/TAGS; $n$-leg: $3 \mathrm{~N} \mathrm{PbTe/2N} \mathrm{PbTe]} \mathrm{is} \mathrm{the} \mathrm{doping} \mathrm{of} \mathrm{the}$ $\mathrm{n}$-type $\mathrm{PbTe}$ with additional $\mathrm{Te}$ vaporized from the $\mathrm{p}$ leg, since this is the most volatile element in this system. As described below no interaction or diffusion of the thermoelectrics was observed through a zirconia barrier.

\section{Interaction between molten TAGS and zirconia at $800^{\circ} \mathrm{C}$.}

In the first test a small piece of yttria-stabilized zirconia, 0.5-mm thick, was sealed in a quartz tube with $2.68 \mathrm{~g}$ of TAGS in an $\mathrm{Ar}-3 \% \mathrm{H}_{2}$ atmosphere. The materials were heated to $800^{\circ} \mathrm{C}$ (above the melting point of TAGS) and held at that temperature for 98 hours with the zirconia immersed in the molten TAGS. At the conclusion of the test when the tube was opened no evidence of wetting of the zirconia by the TAGS was seen, although the TAGS did have a "grey" coloration; the walls of the quartz tube had a significantly darker (thicker) deposit.

The zirconia, the TAGS and the deposit on the surface of the tube were analyzed with a scanning electron microscope (SEM). Significant decomposition of the TAGS had taken place and three rather distinct surface regions were seen on the material, 1) a shiny area with inclusions of bubbles, 2) a grey area and 3) another grey area, but with a significantly different texture. Table 1 summarizes the compositions of these areas as determined by the SEM and compares them with the nominal composition of TAGS. The deposit on the inner surface of the quartz tube was approximately 60 at\% Ge and 40 at\% Te. The thin deposit on the zirconia was "transparent" and not measurable; it contained less than 0.1 to 0.2 at\% Te or Ge.

Table 1. Composition of TAGS after Contact with Zirconia at $800^{\circ} \mathrm{C}$

(Measured with SEM)

\begin{tabular}{|c|c|c|c|c|}
\hline Area & Te & Ag & Ge & Sb \\
\hline Nominal TAGS & 50.00 at\% & 6.52 at\% & 36.96 at\% & 6.52 at\% \\
\hline Shiny, bubbles & 50.13 at\% & 11.05 at\% & 31.78 at\% & 6.95 at\% \\
\hline Grey area 1 & 47.70 at\% & 10.17 at\% & 35.44 at\% & 6.69 at\% \\
\hline Grey area 2 & 57.53 at\% & 10.99 at\% & 25.05 at\% & 6.43 at\% \\
\hline
\end{tabular}

Finally the zirconia was broken to give a clean surface through its cross section. No Te or Ge was detected by the SEM/EDX analysis in this cross section, including locations within $10 \mu \mathrm{m}$ of the surface, again to the limits of 0.1 to 0.2 at\%. 


\section{Diffusion through zirconia at $500^{\circ} \mathrm{C}$}

In order to evaluate the possibility of longer-term diffusion through the barrier of a zirconia eggcrate and resultant cross contamination of the legs, a double-chamber graphite crucible was constructed with a zirconia barrier separating the chambers. A sample of TAGS was mounted in one chamber and one of 3N/2N PbTe was mounted in the other. Figure $2 a$ is a drawing of the cross section of the crucible and Figure $2 b$ shows how the samples and supports were configured in the chamber and the sealing of the chambers and barrier. 0.4-mm-thick grafoil was used for the gaskets. The venting hole in the connecting ring was located so that if excessive pressure forced a species to blow by the gasket it would be vented outside of the crucible rather than being forced into the adjacent chamber. All of the graphite parts, except the grafoil, were cleaned by heating to $2000^{\circ} \mathrm{C}$ in vacuum before assembly.

With the samples and barrier mounted in the crucible, it was sealed in a quartz tube in $\mathrm{Ar}-3 \% \mathrm{H}_{2}$, at one-half atmosphere pressure, mounted in a furnace and held isothermally at $500^{\circ} \mathrm{C}$ for 2834 hours.

The resistivity and Seebeck coefficient of the PbTe and TAGS used in the test were measured before they were mounted in the crucible and these data were compared with the post-test values. The properties of the TAGS were measured as a function of temperature and those of the PbTe were measured at room temperature. [Because of the small size of the available $\mathrm{PbTe}$ samples it was not possible to instrument the sample with thermocouple/voltage probes to make temperature dependant measurements. See Section 2.5 for comments on uncertainties in the effective spacing of close-spaced probes.]

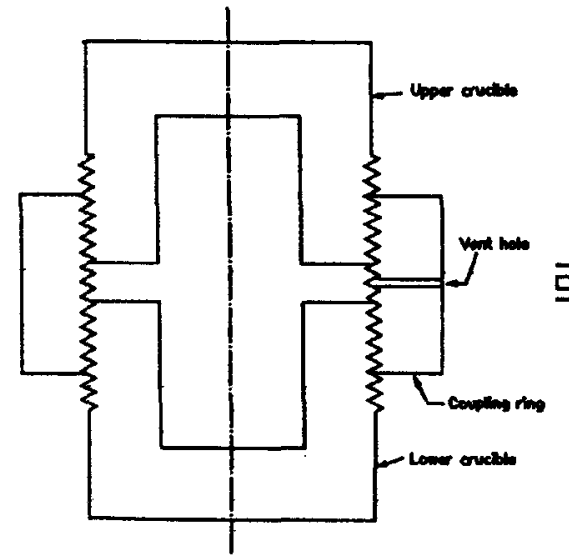

a)

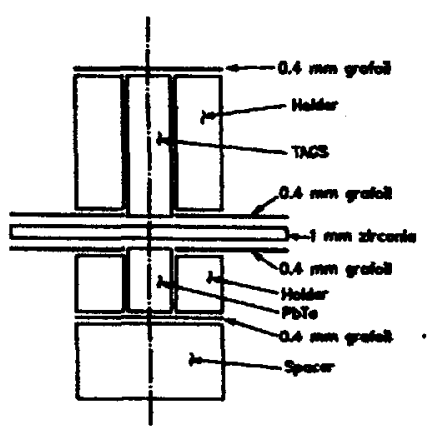

b)

Figure 2. Configuration of Graphite Chamber used in Long-Term Diffusion Tests 
The temperature-dependent resistivity and Seebeck coefficient of the TAGS were measured in helium atmosphere. Two thermocouple/voltage probes were attached to sample bar by wedging them in $0.40-\mathrm{mm}$ holes drilled into the side of the sample. Fourprobe measurement of resistivity was made using these voltage probes and pressure current contacts were made to the ends of the samples through graphite electrodes with grafoil pads. These contacts were held at a temperature difference of 50 centigrade degrees which typically resulted in a temperature difference across the probes of 15 to 20 degrees, providing the temperature gradient for measurement of the Seebeck coefficient. The measured resistivity and Seebeck coefficient were reported at the average of these temperatures.

Figure 3 compares the resistivity and Seebeck coefficient before and after the 2834-hour period at $500^{\circ} \mathrm{C}$. The minimal change in these properties seems to indicate that TAGS undergoes little or no decomposition or vaporization of constituents at $500^{\circ} \mathrm{C}$.

The room-temperature resistivity of the segmented $\mathrm{PbTe}$ sample was measured using a four-probe method in which a sample, clamped between current electrodes at its end, is translated under a voltage probe at a fixed location. The second voltage probe is connected to one of the current contacts; as a consequence the measured resistance include the (fixed) contact resistance at one end. However the change in resistance as a function of distance along the sample yields the true sample resistivity. This apparatus is especially useful for measurement of the resistance of the joint between segments of a segmented leg. Figure 4 shows the resistance verses distance before and after the 2834 hour test at $500^{\circ} \mathrm{C}$. The data are plotted with the "break" at the joint match at Location $=0, R=0$ (for the initial measurement) and $R=0.2$ (for the measurement after the test), since only the slope of the resistance data is relevant. There are small differences in the slopes, but it can be concluded that no significant change occurred in the resistivity of the segments.
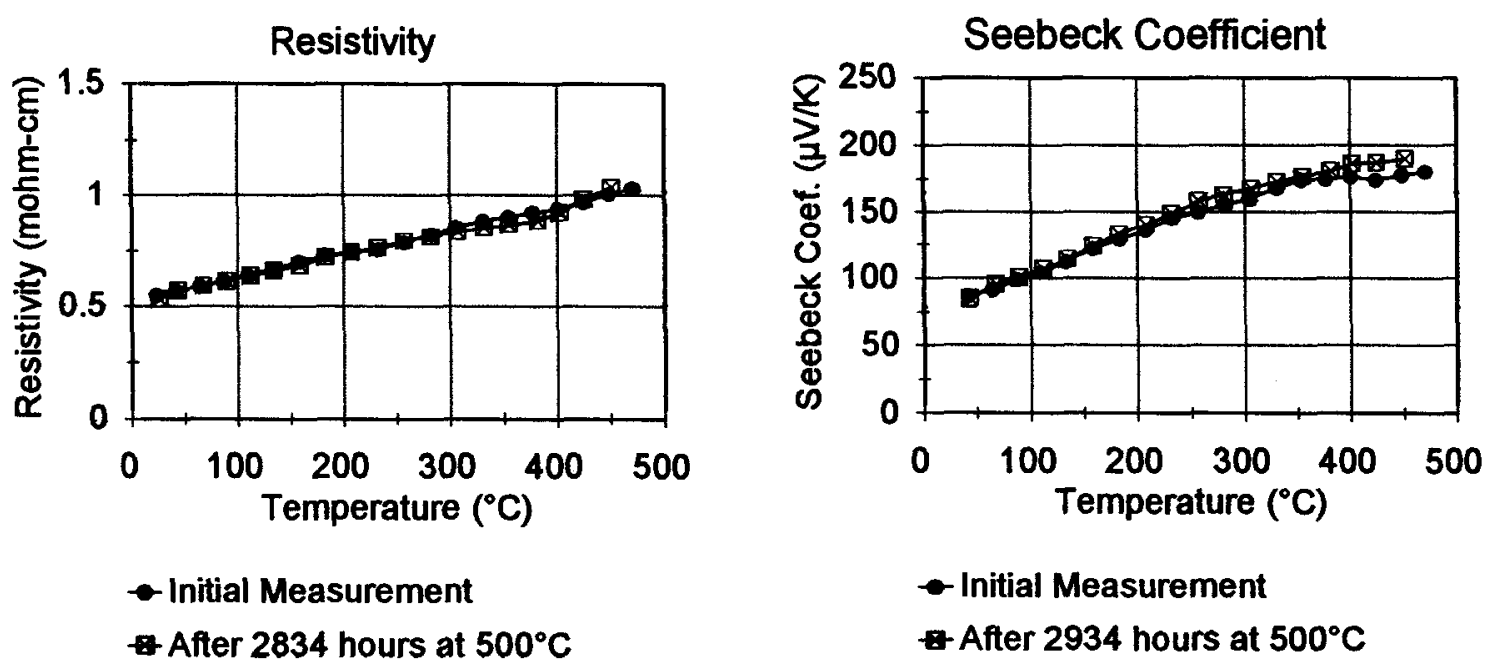

Figure 3. Resistivity and Seebeck Coefficient of TAGS Sample 165-5 A1, Before and After 2835 Hour Diffusion Test at $500^{\circ} \mathrm{C}$. 


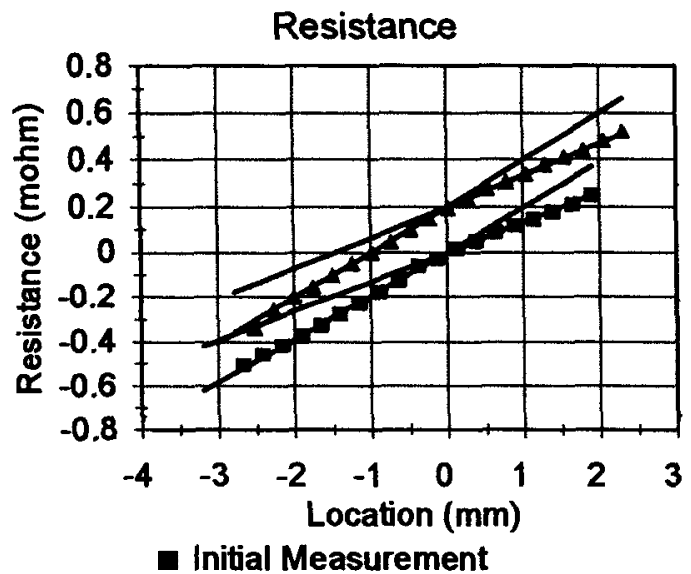

- After 2834 hours at $500^{\circ} \mathrm{C}$
Figure 4. Room Temperature Resistance of Segmented PbTe Sample as a Punction of Position on Surface Before and After 2834 Hour Test at $500^{\circ} \mathrm{C}$.

The effective Seebeck coefficient $(\Delta V / \Delta T)$ was measured in an apparatus used primarily for screening of samples at $\Delta T \cong 75^{\circ} \mathrm{C}\left(T_{\text {hot }} \simeq 100^{\circ} \mathrm{C}, T_{\text {cold }} \cong 25^{\circ} \mathrm{C}\right)$. The values before and after the long-term test were $142 \mu \mathrm{V} / \mathrm{K}$ and $138 \mu \mathrm{V} / \mathrm{K}$. This difference in the Seebeck coefficient is well within the scatter typically seen in measurements with this apparatus.

The TAGS sample from this test was mounted and polished and its composition was measured with the SEM. As documented in Table 2 the measurement shows a somewhat reduced concentration of $\mathrm{Ag}$ and $\mathrm{Sb}$ with increased $\mathrm{Ge}$ as compared to the nominal concentrations. These results may be within the scatter of the SEM measurement, but are somewhat larger than would be normally expected. Unfortunately this sample was not measured prior to the long term test, but another sample cut from the same boule shows concentrations for the most part closer to the nominal values, as shown also in Table 2.

\section{Table 2}

Measured Composition of TAGS Sample (166-5A1) Used in Long Term Test. Comparison with Nominal Values and with Another Sample (166-63) Cut from the Same Boule

\begin{tabular}{|c|c|c|c|c|}
\hline & Te & Ag & Ge & Sb \\
\hline \hline 166-5A1 (after test) & 50.12 at\% & 5.65 at\% & 39.15 at\% & 5.08 at\% \\
\hline 166-63 (before test) & 50.43 at\% & 6.17 at\% & 37.85 at\% & 5.56 at\% \\
\hline Nominal TAGS & 50.00 at\% & 6.52 at\% & 36.96 at\% & 6.52 at\% \\
\hline
\end{tabular}

It is difficult to assess these results which show that the concentration of the minor constituents, $\mathrm{Ag}$ and $\mathrm{Sb}$, were reduced resulting in increased concentrations of Te and Ge. We do conclude however that $\mathrm{Te}$, which we expected to be the most volatile element, is stable. In addition any possible changes in relative concentrations did not affect the resistivity or Seebeck coefficient. 
The $\mathrm{PbTe}$ sample was the most changed visually. Its surface which was initially dull grey was shiny and metallic-looking after the test. In addition the surfaces were covered with small $(\approx 20 \mu \mathrm{m})$ crystallites, most of which as judged from their shapes were single crystals. Analysis of these crystallites showed they had the same composition as the base material, which was also no different than that of another sample which had not been subjected to the long term heating. See Table 3. Whether these crystallites were formed by vaporization and recrystallization of material (which seems somewhat unlikely in an isothermal situation) or simply surface migration of material is uncertain.

Table 3

Composition of PbTe Sample from 2834 Hour Test Comparison with Unheated Sample

\begin{tabular}{|c|c|c|}
\hline & $\mathrm{Pb}$ & $\mathrm{Te}$ \\
\hline \hline Base Material & 46.38 at\% & 53.62at\% \\
\hline Crystallites & 46.26 at\% & 53.74 at\% \\
\hline Control Sample & 46.44 at\% & 53.56 at\% \\
\hline
\end{tabular}

Finally the zirconia barrier was analyzed, both on the surface, which had a very slight coloration, and in the cross section obtained by breaking the sample. Only $\mathrm{Zr}$ and $O$ were seen. As in the earlier measurement the sensitivity for detection of $\mathrm{Zr}$ was $\leq 0.1$ to 0.2 at\%. Yt was not detected, but would be very difficult to see in the known concentration ( $<10$ at\%) because its primary peak occurs on the shoulder of the primary $\mathrm{Zr}$ peak.

From all of these results we conclude that yttria-stabilized zirconia is a highly recommended material for fabrication of ceramic eggcrates for high-temperature, closespaced thermoelectric modules for long term operation.

\section{Diffusion through Mica/Tungsten/Mica}

Concurrent with the long-term measurement with the zirconia barrier a second similar test was performed using a barrier consisting of a sheet of $10-\mu \mathrm{m}$ tungsten sandwiched between sheets of $100-\mu \mathrm{m}$ mica. This configuration was tested as a possible back up to the zirconia in case the latter proved ineffective in precluding transport between the $p$ - and $n$-legs or if injection molding of the required structure was not successful. It was recognized that this approach, if necessary, would likely be more difficult to implement since an eggcrate fabricated of sheets of material would likely have "leaks" between compartments. Sealing them would be problematical. This approach as indicated below is also positive in preventing interaction between $\mathrm{n}$ - and p-legs. However additional development of this type of eggcrate should only be pursued if the injection molding of larger eggcrates of $\mathrm{ZrO}_{2}$ is not feasible. 
The test crucible used with the mica/W/mica barrier was similar in construction to that used for the zirconia barrier; it differed only in details as to how the barrier was clamped between the chambers. This crucible was sealed in the same quartz tube at the one with the zirconia barrier and consequently experienced an identical period at temperature.

The largest change in the electrical properties after the test was in the resistivity of the TAGS sample, which actually was reduced from the pre-test value. The Seebeck coefficient of this sample was essentially unchanged except above $\approx 400^{\circ} \mathrm{C}$ where it was slightly reduced. As a consequence the Power Factor for this sample was increased over most of the temperature range after the 2834 hour test.

No evidence of deposits was seen on the surfaces of the mica using the SEM.

\subsection{MATERIALS FABRICATION}

TAGS. A 200-g sample of TAGS [(AgSbTe $\left.)_{0.15}(\mathrm{GeTe})_{0.85}\right]$ was prepared by loading the stoichiometric amounts of the elemental materials into a quartz tube which was evacuated and backfilled with $\sim 1 / 2$ atmosphere of $\mathrm{Ar} / 3 \% \mathrm{H}_{2}$. The tube was loaded into a rocking furnace, heated to $850^{\circ} \mathrm{C}$ and held for a total of 60 minutes; the melt was rocked 10 times every 15 minutes. It was then transferred to an aging furnace and held at $500^{\circ} \mathrm{C}$ for 48 hours.

SnTe. A 200-g sample of SnTe was similarly prepared by loading the stoichiometric amounts of the Sn and Te into a quartz tube which was evacuated and backfilled with $\sim 1 / 2$ atmosphere of $\mathrm{Ar} / 3 \% \mathrm{H}_{2}$. The tube was loaded into a rocking furnace, heated to $850^{\circ} \mathrm{C}$ and held for a total of 60 minutes; the melt was rocked 10 time every 15 minutes. It was then transferred to an aging furnace and held at $500^{\circ} \mathrm{C}$ for 48 hours.

PbTe. Segmented legs of 3N/2N PbTe which had been fabricated several decades ago at General Atomic were available at $\mathrm{Hi}-\mathrm{Z}$ and were used for the $\mathrm{n}$ legs in the present study. The exact details on the preparation of the $\mathrm{PbTe}$ are not known for these specific samples, but n-type material typically is prepared from $61.05 \mathrm{wt} \% \mathrm{~Pb}$ and $38.30 \mathrm{wt} \% \mathrm{Te}$ with added $\mathrm{PbI}_{2}$. 2N material normally contains $0.076 \mathrm{wt} \% \mathrm{PbI}_{2}$ and $3 \mathrm{~N}$ material 0.14 wt\%. The constituents would be sealed in a quartz tube in an Ar- $\mathrm{H}_{2}$ atmosphere, and heated above $922^{\circ} \mathrm{C}$, the melting point of $\mathrm{PbTe}$, probably in a rocking furnace, and subsequently annealed.

These segmented legs were formed by co-hot-pressing powders of $2 \mathrm{~N}$ and $3 \mathrm{~N}$ material ground from the cast ingots. Measurement of the resistance profile along the side of the legs showed considerable variability in the relative lengths of the segments. Legs with approximately equal length segments were chosen by this screening technique. 


\subsection{SAMPLE PREPARATION AND EVALUATION}

In order to evaluate the polycrystalline, cast material, samples for measurement of TAGS and SnTe were cut from the boules with an internal diamond saw. Measurements of the temperature dependence of the resistivity and Seebeck coefficient were made on samples $0.60 \times 0.60 \mathrm{~cm}$ square and $1.5 \mathrm{~cm}$ long. Two thermocouple/ voltage probes, separated by $\sim 1 \mathrm{~cm}$, were attached to the side of the sample by wedging them into 0.4-mm diameter, drilled holes, typically $1.5 \mathrm{~mm}$ deep. Pressure current-contacts were made to the end of the sample using graphite electrodes; to assure uniform contact a layer of $0.4-\mathrm{mm}$ thick grafoil was placed between the electrodes and the ends of the samples. A temperature difference of $50^{\circ} \mathrm{C}$ was maintained between the electrodes (typically about half of the temperature drop occurred at the end contacts). Data were usually taken in $25^{\circ} \mathrm{C}$ increments of temperature. Sample resistance was measured with a four-probe resistance bridge. Seebeck coefficient was determined by sequential measurement of the d.c. voltage across the voltage/thermocouple probe and the temperature recorded by both thermocouples. The data are reported at the average of the temperature recorded by the probes.

Figure 5 shows the measurements on a TAGS sample and compares it with reference values. It will be noted that the resistivity of this sample is significantly lower than the reference values and that the Seebeck coefficient is somewhat lower. These combine to yield a calculated Power Factor which is similar to the reference value up to about $250^{\circ} \mathrm{C}$ and somewhat higher above this temperature. All of our measurements on TAGS show similar results. Figure 6 (SnTe 165-7-1) shows results of measurements on SnTe. Again both resistivity and Seebeck Coefficient of our material are lower than the
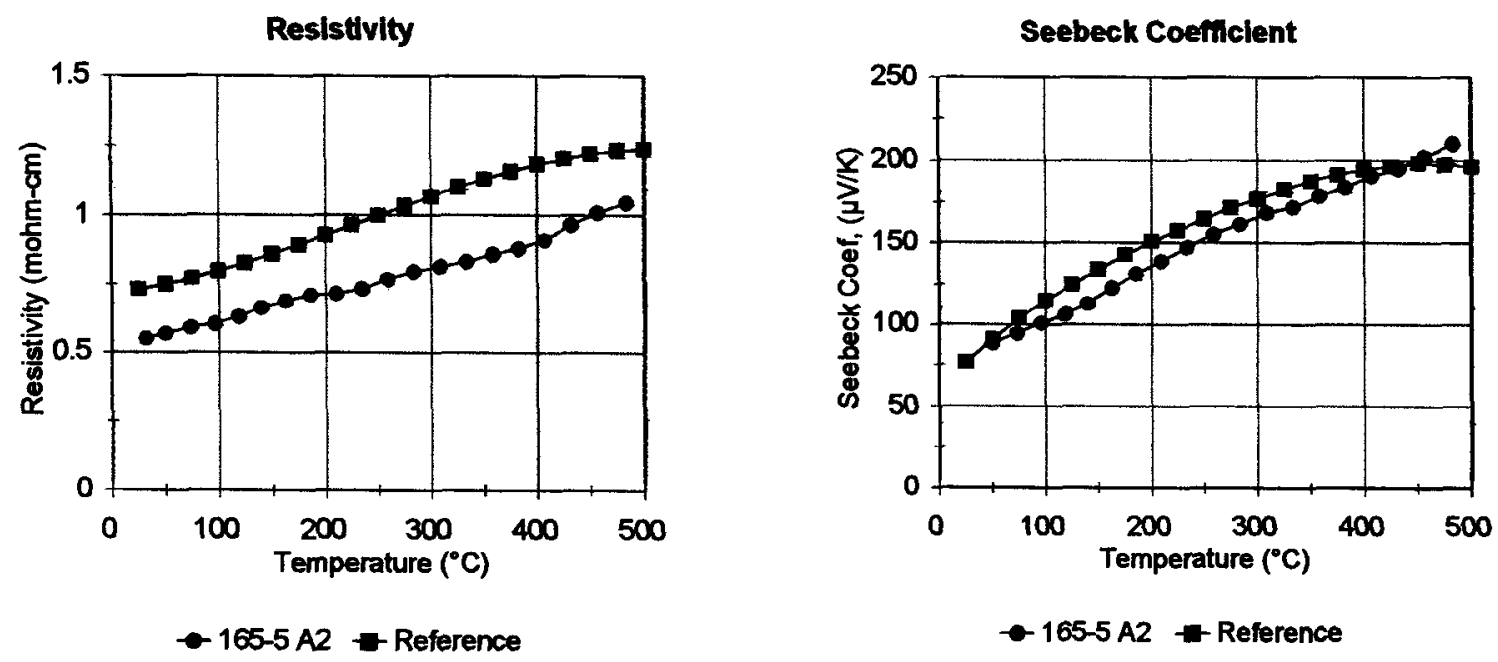

Figure 5. Temperature Dependence of Resistivity and Seebeck Coefficient of TAGS Sample 165-5 A2 

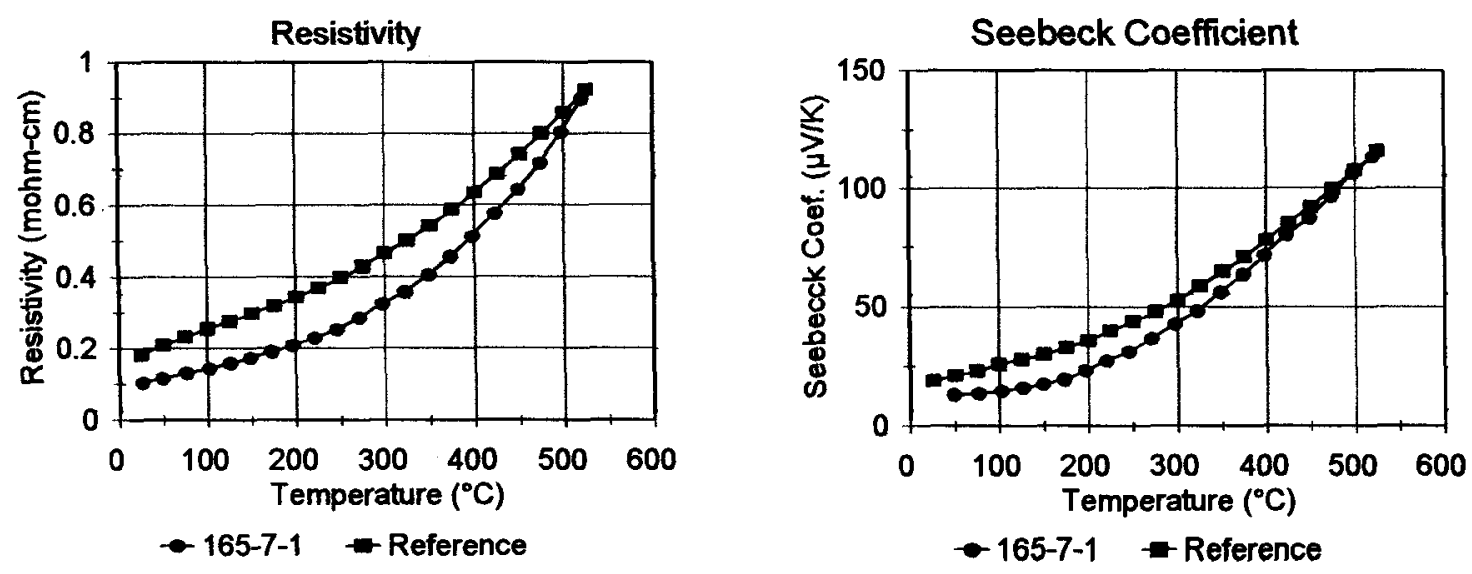

\section{Figure 6. Temperature Dependence of Resistivity and Seebeck Coefficient of SnTe Sample 165-7-1}

reference values, and in this case yield Power Factor values which are similar to the reference values over most of the measured temperature range.

\subsection{JOINING OF TAGS AND SnTe}

Previous work at General Atomic and Teledyne in the early 70's showed that TAGS and SnTe could be joined by co-hot-pressing powders of the two materials. Such a technique yielded mechanically strong, low-resistance joints. Although in the present program use of previously cast material for the segments of the legs was desired, use of SnTe to join the segments seemed reasonable.

In order to obtain segmented legs on which it would be easy to measure the temperature-dependent, electrical properties of both of the segments in addition to the resistance of the joint, the preliminary bonding tests were carried out using segments which were $0.75-\mathrm{cm}$ long. The cross-section of these legs was $0.62 \times 0.62 \mathrm{~cm}$, the same dimensions as planned for the legs to be used in the eggcrate.

Joining was carried out using a graphite die with a square bore which was 25 to $50 \mu \mathrm{m}$ larger than the cross-sectional dimensions of the legs. Load was applied to the stack to be joined through square graphite plungers using a small vacuum hot press in which induction heating was used; the graphite die served as the susceptor for the induction heating. Sample temperature was determined with a stainless-steel-clad thermocouple inserted into a hole in the side of the die. The previous hot-pressing and joining studies showed that good materials and joints could be obtained at temperatures between 480 and $500^{\circ} \mathrm{C}$, and at a load of $500 \mathrm{psi}$. These values served as the base line for the present work.

A total of 12 bonding runs were made, using SnTe in two different forms, ground $\mathrm{SnTe}$ powder and a mixture of Sn and Te in the proper stoichiometric ratio to yield SnTe 
when reacted. The amount of powder used in the various runs, if fully densified in the pressing/reaction, would yield a joint thickness in the range between 100 and $200 \mu \mathrm{m}$. Some uncertainty exists in the load used in joining. Because of the small cross-sectional area of the sample, the hot press was used in a load range only perhaps $20 \%$ above the value needed to move the piston. However experience over the course of the studies and measurements with a load cell convinced us that settings were reproducible from run to run. Table 4 summarizes the bonding series.

The bonding runs labeled "vacuum" were carried out in a chamber being actively pumped with a diffusion pump. Although the ion gauge could not be operated while the induction heater was in operation, the pressure measured before the start of the heating cycle was $\leq 5 \times 10^{-5}$ torr. The runs labeled " $\mathrm{Ar} / 3 \% \mathrm{H}_{2}$ " were carried out in $\sim 2 / 3$ atm of this gas. The chamber was first pumped to $\leq 5 \times 10^{-5}$ torr and then backfilled with the $\mathrm{Ar}-\mathrm{H}_{2}$. In all runs the temperature was increased over a period about 20 minutes to $500^{\circ} \mathrm{C}$, held there for 15 minutes and then cooled over about 20 minutes to a temperature below $\sim 80^{\circ} \mathrm{C}$. Cold pressing of the $\mathrm{Sn}$ and Te mixture in sample 166-77, prior to hot pressing was done in air in the hot press and then the chamber was evacuated. For samples 166105 and -113 cold pressing was done in vacuum and then the chamber was backfilled with $\mathrm{Ar}-\mathrm{H}_{2}$. In addition for these two samples the load was applied to the sample prior to beginning of the heating cycle and manually maintained at that value throughout the period of heating, holding at $500^{\circ} \mathrm{C}$, and cooling. In earlier runs the load was allowed to increase as the heating occurred, was increased to the final value when $500^{\circ} \mathrm{C}$ was reached, and then was allowed to drop during the cooling cycle.

Although good electrical properties and a good bond strength were obtained both with SnTe power and with the mixture of $\mathrm{Sn}$ and Te powder which reacted during pressing, it appears that these could be achieved in the latter case at a lower load. This would seem to be desirable since in most of the joining runs cracks were created in the TAGS portion of the leg. It is likely that in most cases these are surface cracks, since they had no apparent effect on the electrical conductance of the material. The calculated electrical resistivity of the "cracked" material was identical to that of the reference value of the boule from which it was cut. A second reason to favor lower loads was the observation in the runs at the highest loads of flow of material at the outer ends of the leg around the ends of the plungers which is better avoided.

\subsection{MEASUREMENT OF RESISTIVITY AND SEEBECK COEFFICIENT}

As mentioned above these test samples were fabricated with a length to allow measurement of the resistivity and Seebeck coefficients of both segments as well as the resistance of the joint. In order to accomplish this the temperature-dependent resistivity and Seebeck coefficients were measured in the same manner as described above in Section 2.3. Instead of using two thermocouple/voltage probes on the side of the sample, four were mounted, with the middle pair just spanning the region of the joint. Temperature measurements were made at all four locations, four-probe resistance measurements were made on the TAGS, the SnTe and the joint region, and the Seebeck voltage was measured across the TAGS and SnTe portions. Figure 7 shows the results of this measurement series for sample 166-113. 


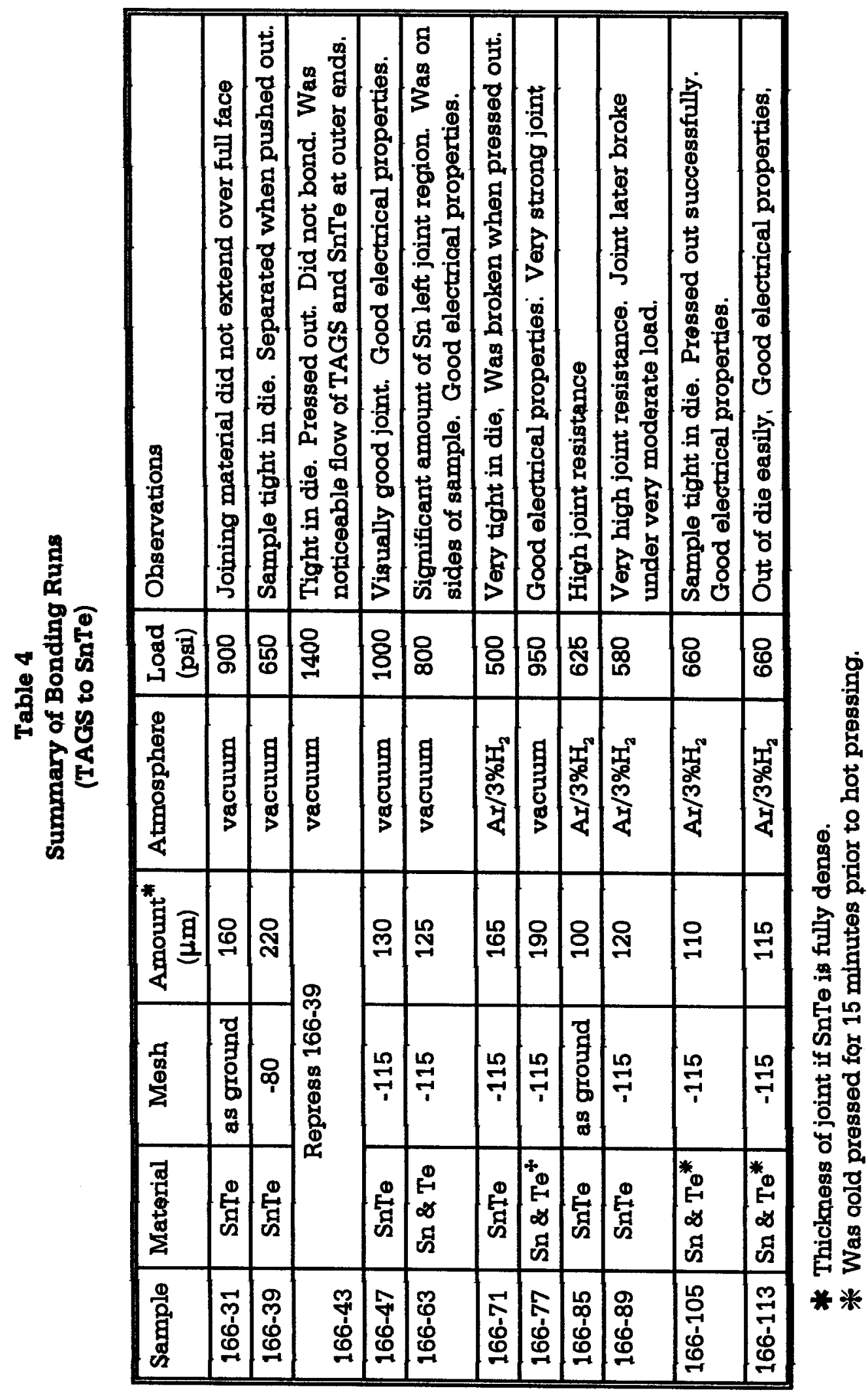

